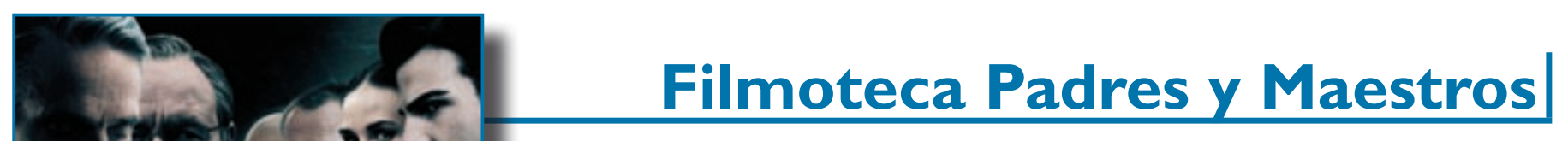

\title{
MIPRINAII
}

FP, Bachillerato, Universidad, Formación Docente

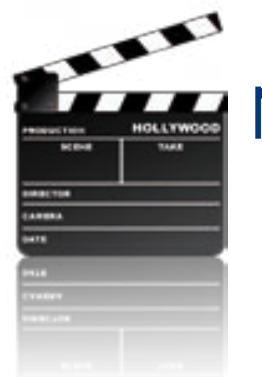

Margin Call

Carmen Pereira Domínguez y Luis Fernando Valero Iglesias mcdguez@uvigo.es y lvi@tinet.org

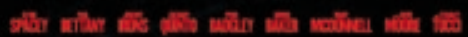

«Si nos hubiéramos comportado éticamente, no tendríamos una crisis como la actual»

Adela Cortina

\section{Ficha técnica}

TÍTULO ORIGINAL: Margin Call

NACIONALIDAD: EE.UU.

DIRECCIÓN: J. C. Chandor

GUIÓN: J. C. Chandor

PRODUCTORA: Lionsgate Films / Myriad Pictures /

Benaroya Pictures

AÑO: 20II

INTERPRETACIÓN: Sam Rogers (Kevin Spacey),

Will Emerson (Paul Bettany), John Tuld (Jeremy Irons),

Peter Sullivan (Zachary Quinto), Seth Bregman (Penn

Badgley), Jared Cohen (Simon Baker), Mary Rogers

(Mary McDonnell), Sarah Robertson (Demi Moore),

Eric Dale (Stanley Tucci)

MÚSICA: Nathan Larson

FOTOGRAFÍA: Frank G. DeMarco

GÉNERO: Thriller. Drama. Crisis social

DISTRIBUCIÓN: Wanda Vision

DURACIÓN: 109 minutos

WEB OFICIAL: http://www.margincallmovie.com/

PREMIOS 20II: Oscars: Nominada a mejor guión original; Festival de Berlín: Sección oficial largometrajes;

Círculo de críticos de Nueva York: Mejor debut;

National Board of Review: mejor nuevo director;

Premios Gotham: Nominada a mejor reparto;

Independent Spirit Awards: Mejor ópera prima.

Nominada a mejor guión novel

\section{La historia}

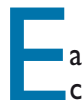

a película está ambientada en el temerario mundo de las finanzas, plasma la situación de Wall Street y retrata las conductas del poder financiero. El thriller narra la crónica de la vida de ocho trabajadores de un poderoso banco de inversión durante las veinticuatro horas previas al comienzo de la crisis financiera del año 2008. Cuando un brillante analista principiante revela una información que podría causar la quiebra de la empresa, se desencadena una amalgama de decisiones tanto morales como financieras que producen una hecatombe en la vida de los implicados, en el entorno económico y financiero que más tarde tendrá repercusiones a nivel mundial.

\section{Temas}

- Conciliación laboral y familiar

- Consumo racional y justo

- Educación familiar

- El despido y sus consecuencias

- El libre albedrío

- La crisis económica y su impacto social

- La formación profesional

- La formación emocional

- Las relaciones en el trabajo

- Reinserción laboral

- Trabajo, dinero y ambición

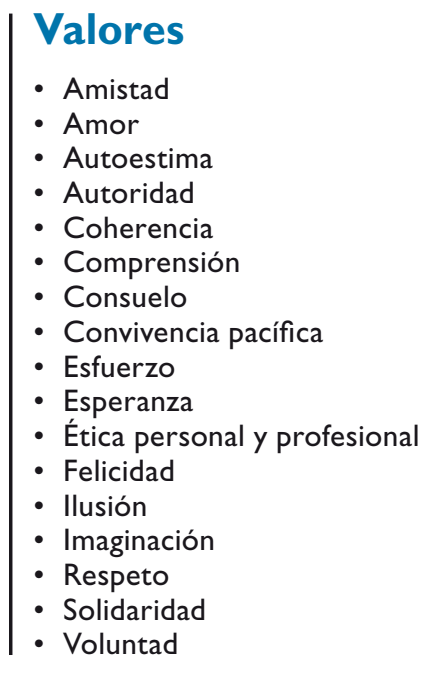

\section{Antes de ver la película}

I. Nos situamos en Wall Street, centro mundial de los negocios y tratamos de aprender sobre el origen, los objetivos y el funcionamiento de la bolsa, de los bancos y el sector financiero.

2. Conocemos la trayectoria vital, profesional y ética de personas dedicadas al mundo de las finanzas.

3. Indagamos sobre las cajas de ahorros (antes denominadas cajas de ahorros y monte de piedad) y su obra social. Destacamos algunas de ellas.

4. Buscamos la historia, los objetivos y las Fundaciones creadas por los bancos en nuestro país: La Caixa, Juan March, Pedro Barrié de la Maza, Banco de Santander...

5. ¿Qué relación existe entre personajes célebres con fundaciones, ONGs y otros organismos de carácter social?

6. En Internet localizamos información que analice el origen de la crisis de 1929 y la actual.

7. Nos documentamos sobre las grandes escuelas de negocios y sus efectos positivos y negativos ante la crisis.
8. También nos informamos sobre programas referidos al paro, búsquedas de empleo, emprendedores, reinserción laboral, trámites administrativos relacionados con el mundo del trabajo, subsidios existentes para parados de larga duración..., ¡conocemos personas en esas situaciones?, ¿cómo nos afecta todo este abanico de cuestiones?

9. Visitamos un banco y percibimos en su entorno las consecuencias de la crisis (escasos empleados, pocos clientes, manifestaciones en la entra$\mathrm{da}$, pintadas en las instalaciones...).

10. Conocemos los microcréditos de Muhammad Yunus, fundador del Banco Grameen, esos pequeños préstamos concedidos a personas humildes que no pueden solicitar una ayuda bancaria tradicional.

II. ¿Qué sabemos de la Fundación Vicente Ferrer en la India y sus acciones sociales?

12. Nos enteramos sobre el funcionamiento de bancos de alimentos y organizaciones como Cáritas.

13. Nos fijamos en la carátula del filme, la describimos y exponemos nuestras impresiones. Buscamos en Internet qué significa Margin Call. 


\section{Algo serio está ocurriendo...}

I. Al inicio de la película vemos una panorámica de la ciudad de Manhattan, con sus rascacielos. A la vez, escuchamos una música de suspense. La cámara se centra en la actividad diaria de una entidad financiera. Un grupo de personas caminan serias por la oficina.

I.2. Will Emerson, el segundo del departamento comercial comenta: "iHabéis pasado alguna vez por esto? Es mejor no hacer caso, bajar la cabeza y seguir currando. ¡Vamos, no miréis!” (I’46”).

I.3. Tras diecinueve años en la firma deciden prescindir de Eric Dale, un experto en control de riesgos. Desde el Departamento de Recursos Humanos se lleva a cabo el despido masivo, sin previo aviso le comunican: "Vivimos momentos especialmente difíciles como usted debe saber muy bien... Esto no es nada personal, la mayor parte de la plantilla será despedida... Su e-mail de empresa, el acceso al servidor, el acceso al edificio, su móvil y su línea de teléfono quedarán bloqueados a partir de este momento y este caballero lo acompañará a su despacho para que recoja sus objetos personales" (3'36").

- "La firma ha elaborado un plan de transición..., aquí está mi tarjeta y puede ponerse en contacto conmigo si necesita ayuda en este período de transición de su vida" (5'56").

I.4. Una vez hecha la primera criba, Sam Rogers, el gran protagonista, es el responsable comercial de la agencia de bolsa y una persona llena de contrastes. Quedan 33 trabajadores, mientras que el $80 \%$ de la plantilla se ha ido a casa para siempre, les dice: "¡No os oigo! Seguís aún aquí por una razón... Hemos pasado un mal rato despidiéndolos... Los otros se han ido. Vosotros sois los mejores... Esa es vuestra oportunidad. Yo llevo aquí ya 34 años y os aseguro que no es la última vez que paséis por esto..., pero todos sois supervivientes. Mantened la cabeza alta y volved al trabajo, jadelante!" (I2'27").

I.I. ¿Qué nos sugieren estas imágenes?

I.2. ¿Qué presienten estos jóvenes trabajadores?

I.3. ¿Qué tipo de planos abundan?, ¿cómo es el diálogo en esta escena?, ¿cómo actúan estas dos mujeres?, ¿cómo se muestra Eric ante lo que está oyendo?, ¿qué siente y dice?, ipor qué se sigue preocupando por el trabajo que aún no había terminado?, ipor qué no entiende nada?

- ¿Qué objetos debe recoger de su despacho y qué deducimos sobre su vida personal y familiar?, ¿creéis que este hecho se puede justificar argumentando que ha sido mala suerte como le dice Will y qué pensáis de su comportamiento?, ¿qué interrogantes le surgen a Eric?

- ¿Cómo le despiden sus compañeros más allegados?, ¿qué le agradecen y manifiestan?, ¿qué les dice sobre lo que está ocurriendo?, ¿cómo reacciona Eric a la salida del rascacielos, al intentar realizar una llamada por el móvil?, ¿qué le pregunta a Sarah?

I.4. ¿Qué le pasa y preocupa a Sam?, ¿por qué está tan indeciso?
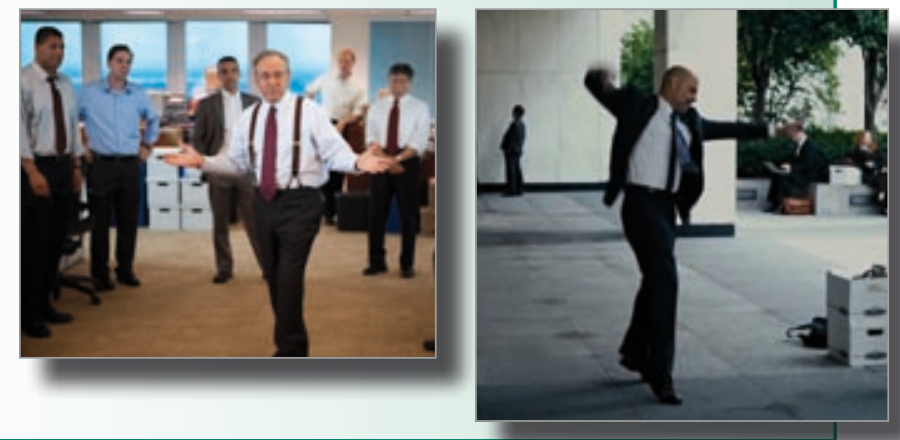

\section{El CONTENido en EL USB}

2.I. Eric, como jefe responsable, antes de marcharse, le entregó una información confidencial en USB a Peter Sullivan (9'48"), un joven analista con dos años de trabajo en la empresa. Es un brillante ingeniero espacial, con un máster y doctorado en la Universidad de Pensilvania. Opta por este puesto ante la tentadora oferta económica ofrecida.

2.2. Al final de la jornada Sullivan se queda en la oficina para terminar el trabajo de Eric y descubre la gravedad del problema. La empresa está al borde de la quiebra ( $\left.16^{\prime} \mid 2^{\prime \prime}\right)$. Preocupado llama a Set y a Will para informarles (17'52"). "Esto es muy gordo", afirman (2l'02"). Intentan encontrar a Sam y exponen el panorama. En esa noche transcurren una serie de reuniones con los más altos ejecutivos (el jefe de la división y la jefa de gestión de riesgos).

2.3. Finalmente, deciden Ilamar al Director General, John Tuld, llega en helicóptero para convocar urgente al comité ejecutivo con los altos directivos y así poder enterarse y remediar la situación. Solicita que Eric exponga en persona su trabajo realizado. Por ello recibirá una generosa recompensa económica (43'10").

Tuld entra en la sala y toma la palabra: "Este asunto hay que tratarlo con urgencia... Sr. Sullivan, hable como lo haría a un niño pequeño..., relájese y hable claro" (43’3I").

2.4. Sam percibe que el mismo equipo humano pasará por otro proceso de despidos en su planta. Se enfrenta a Tuld en el área ejecutiva de comedor y le presenta su renuncia. El jefe le reprocha su actitud y escrúpulos y le expone que la crisis actual no es diferente de otras anteriores, donde ha habido fuertes ganancias e inmensas pérdidas, todo ello forma parte del ciclo económico.

Tuld le ofrece a Sam permanecer en la empresa durante dos años, a cambio de una jugosa gratificación. Sam le avisa a Sullivan que se reúne con Cohen y Tuld informa a Sam que promocionará a Sullivan.
2.I. El currículum vítae de este grupo es sobresaliente y los sueldos percibidos son considerables. El dinero es prioritario para ellos ¿cómo hacen méritos?, ¿cómo van alcanzando cargos superiores?

2.2. ¿Cómo son los planos de esta escena?, ¿qué ambiente se palpa?, ¿qué colores predominan?, ¿cómo es la música que escuchamos? ¿Por qué pensáis que Sam no está en casa y dónde suponen sus compañeros localizarlo?, ¿cómo será su vida familiar?

2.3. Describimos el organigrama de la empresa. ¿Qué cargos representan ahí las mujeres y los hombres?, ¿cómo se comportan y relacionan?, ¿cómo visten?, ¿qué nivel de vida tienen?, ¿cómo se divierten?, ¿qué prioridades establecen?, ¿qué ambiente se respira ahora?
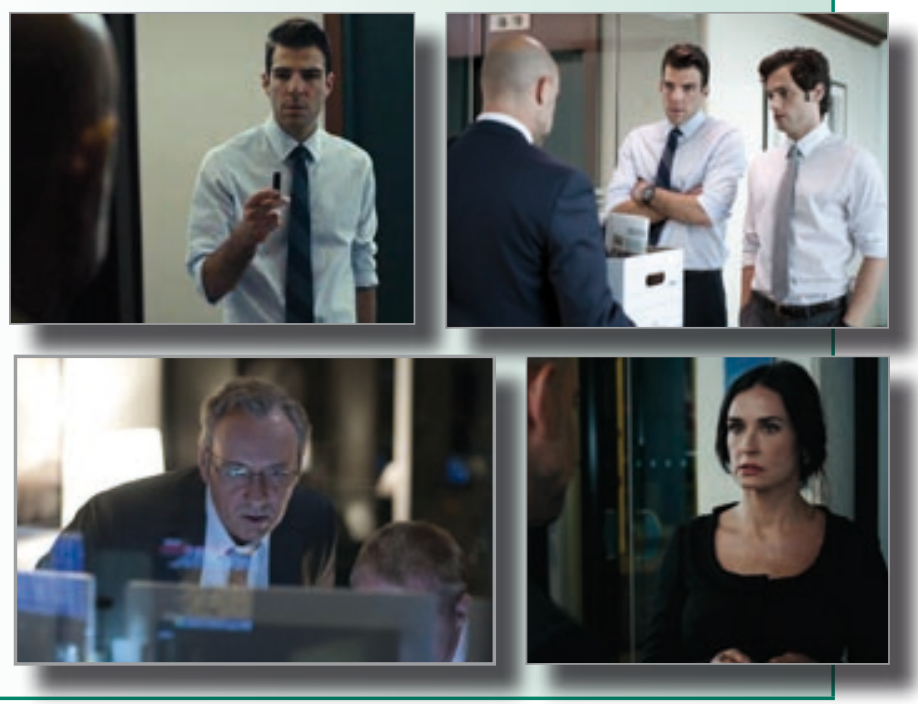


\section{El dinero, Un fin en Sí Mismo}

3.I. En la terraza del rascacielos, a modo de respiro, Will expresa, "Una gran caída... Es el miedo a querer saltar. ¡Hoy no! Parece que nos van a hacer sacar la basura" (37'6").

"Cuando todo acaba ellos no pierden dinero, les da igual que los demás lo hagan, pero ellos no pierden" (38'40").

3.2. Sus compañeros le preguntan a Will: " ¿De verdad que gastaste dos millones y medio el año pasado?, ¿en qué lo gastas?" (38'56").

3.3. Will convence a Eric para ir a explicar la situación de la empresa y le dice: " $i S a b e s$ que una vez construí un puente? Yo era ingeniero de profesión", y explica la de horas que ahorró a esas personas que lo usan, pero Will le comenta: "Algunos disfrutan conduciendo por el camino más largo" (Ih.09'27")

3.4. Tuld habla mientras come con Sam: "Es sólo dinero..., es siempre lo mismo..., ganamos mucho si lo hacemos bien y podemos perderlo todo si lo hacemos mal... Lo haré, tu pequeño discurso no me convence pero necesito el dinero" (Ih.32’26").

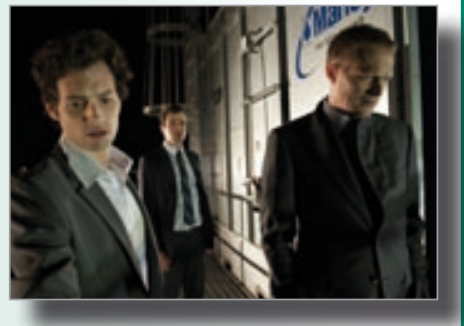

3.I. ¿Cómo se encuentran estas personas para necesitar aire fresco?, ¿de qué hablan?, ¿qué se lee en sus rostros, en sus miradas?

3.2. ¿Consideráis que la clave del éxito de una persona se mide por lo que gana?, ¿por qué los más jóvenes están tan interesados por los sueldos y cómo los gastan?, ¿cuáles son los objetivos de una empresa?, iy los de los trabajadores?, 'hay maneras de entendimiento mutuo?

3.3. ¿Qué importancia tienen las matemáticas en la vida?, iqué interpretamos sobre esta experiencia expuesta por Eric a Will?, icon el dinero se puede comprar todo?, ¿de qué maneras se puede disfrutar la vida?

3.4. ¿En qué se basa el discurso de Tuld y por qué no convence a Sam?, ipor qué creéis que Sam acepta?

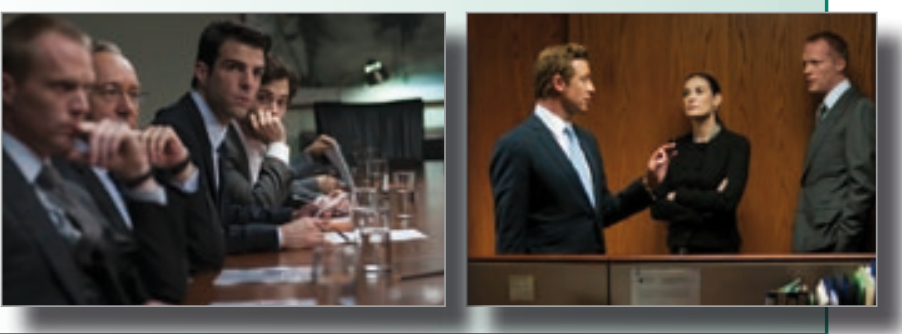

4. Educamos nuestras emociones

4.I. Will le pregunta a Sam si tiene chicles de nicotina y expresa: "Este era el último. Lo cual quiere decir que dentro de diez minutos mataré a alguien" (II'I5").

4.2. Sam está emocionado y le dice a Will: "Mi perra se muere, he hablado con el veterinario, un puto tumor en el hígado, he estado gastando mil pavos al día para mantenerla con vida, no sé qué coño debo hacer" (II'30").

- Más tarde, contemplamos a Sam acompañando en los últimos momentos de vida de su mascota (16'5l”).

4.3. Sarah y Will conversan en el ascensor, en medio se encuentra una señora de la limpieza (55'38”).

4.4. Tuld habla con Sarah Robertson: "No va a ser fácil..., cortaré una cabeza... Cuidaremos muy bien de ti... Te agradecería mucho que no te enfrentaras a mí... Todos hemos jodido esto a lo grande... Necesitamos que te quedes aquí hasta que los mercados cierren" (59'48”).

4.5. Set Bregman, el más joven del grupo está en el baño llorando, al salir ve a Will y le pregunta si le van a despedir diciendo: "Esto es lo que siempre ha querido hacer" (Ih.17'40").

4.6. Sam habla con su grupo de plantilla, les anima con lo siguiente: "Usamos nuestras habilidades para algo bueno" (Ih.25'5I").

- "Creo que conozco a su hijo, es una buena persona", le dice Peter a Sam: "Es lo mejor que se puede decir de una persona" (Ih.l6').

4.7. Al final de la película, Sam, inmenso en una gran tristeza entierra a su perra en el jardín de la casa de su ex mujer, ésta le pregunta qué hace, él responde: "Volvía del veterinario y no se me ocurría otro lugar mejor que este”, “'Estás bien?”, le vuelve a preguntar Mary y él dice llorando: "Ha sido un día horrible” (Ih.35'52").
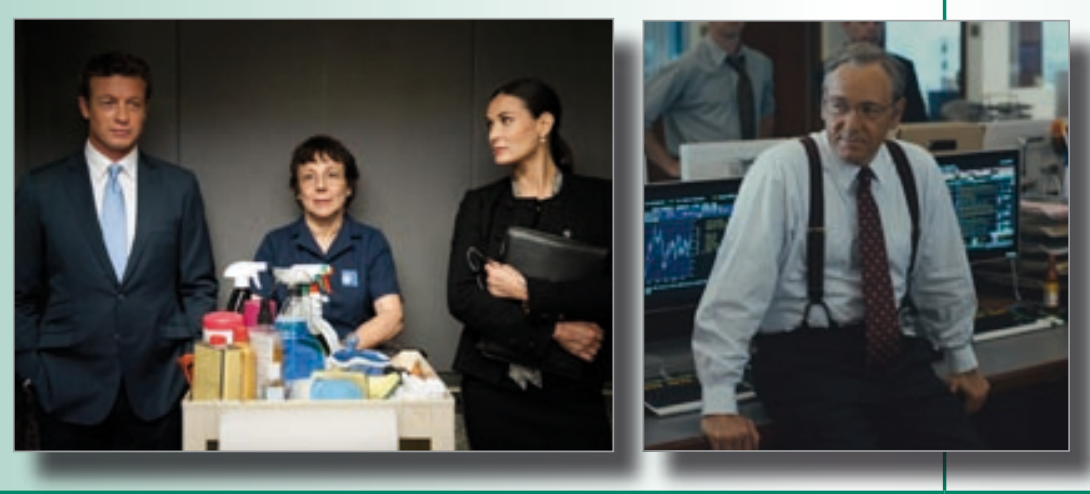

4.I. ¿Cómo controla sus emociones Will?, ¿por qué les llaman a estas personas "tiburones"?

4.2. ¿Qué significa para Sam su perra?, ¿qué hace por ella?, ¿qué sentimientos manifiesta?, ¿qué expresan estas imágenes?, ¿cómo es la música ahora?

4.3. Interpretamos y reflexionamos sobre esta escena, sobre los diferentes tipos de trabajo y estratos sociales y el respeto hacia las personas.

4.4. ¿Cómo suceden estos momentos tensos?, ¿qué tipo de diálogo establecen?, ¿cómo se controlan Sarah y Tuld?, ¿qué tipo de planos predominan?

4.5. ¿Cómo valoráis el comportamiento de Will ante Set?, ¿cómo se desahoga y se controla?, ¿qué tipo de planos de detalle vemos?, ipor qué argumentan que las personas jóvenes son las primeras en caer?

4.6. Explicad cómo las personas influyen para lo bueno y lo malo en las vidas de los demás. Señalamos algún caso de buen y mal ejemplo.

4.7. ¿Qué lecturas podemos hacer sobre la actitud de su ex mujer ante esta escena?, ¿cómo sería la vida anterior de esta pareja?, intentamos comprender este cierre del filme.

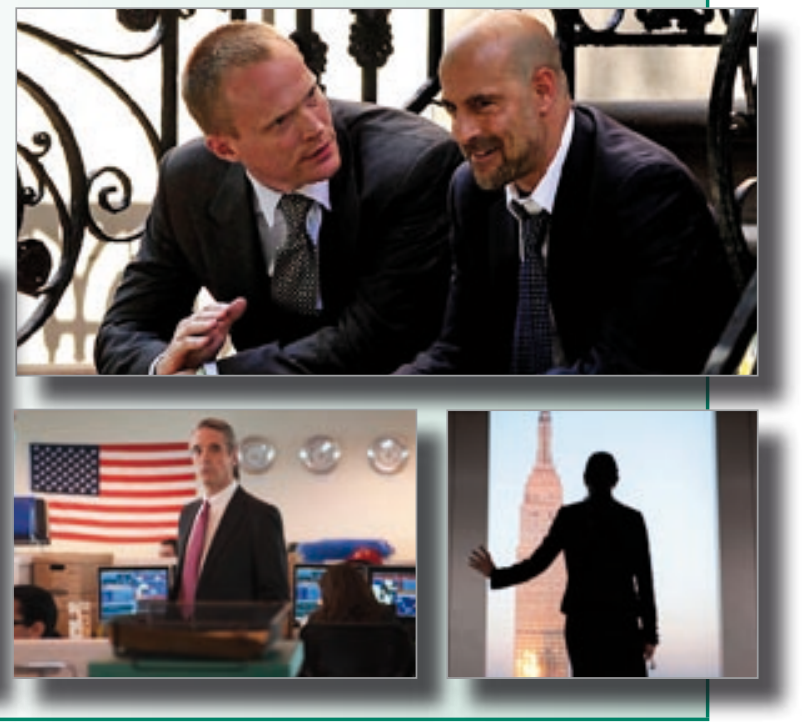




\section{Algunas curiosidades de interés}

I. La película está inspirada en el suceso ocurrido con Lehman Brothers, uno de los grupos de banca de inversión y valores más grandes del mundo, fundado en 1850 en Estados Unidos y su repercusión en la crisis planetaria posterior de 2008 a 2011 .

2. Cuenta con un reparto excelentemente interpretado que convierte el tema sobre finanzas en diálogos atractivos, y consigue reflejar con claridad el problema que está pasando, un estimulante drama.

3. En Argentina este filme se tituló El precio de la codicia.

4. Margin Call es la ópera prima de J. C. Chandor, un director novel de bajo presupuesto. A través de su padre, que trabajó durante cuarenta años en el banco de inversión Merrill Lynch, trata un tema sensible que no deja indiferente a nadie, crónica de la falacia y el cinismo humano ante una situación extrema. Es una auténtica historia humana que permitirá reconocerse a sí mismo: sueños, perversiones y remordimientos.

5. Es una película coral donde se disfruta de un compañerismo gratificante con el resto de los actores estableciendo una gran conexión entre ellos en una reducida limitación de espacios desarrollada casi todo el tiempo en las mismas oficinas y salas de reuniones.

6. Entre los filmes de temáticas parecidas están: Wall Street (O. Stone, EE.UU., 1987); Algo más que un jefe (P. Weitz, EE.UU., 2004); Vamos a hacer dinero (E. Wagenhofer, Austria, 2008); Up in the air (J. Reitman, EE.UU., 2009); Inside job (Ch. Ferguson, EE.UU., 20I0); Wall Street 2: el dinero nunca duerme (O. Stone, EE.UU., 20I0); The company men (J. Wells, EE.UU., 20I0); The flaw (D. Sington, EE.UU.-Inglaterra, 20II); Too big to fail (C. Hanson, EE.UU., 20II).
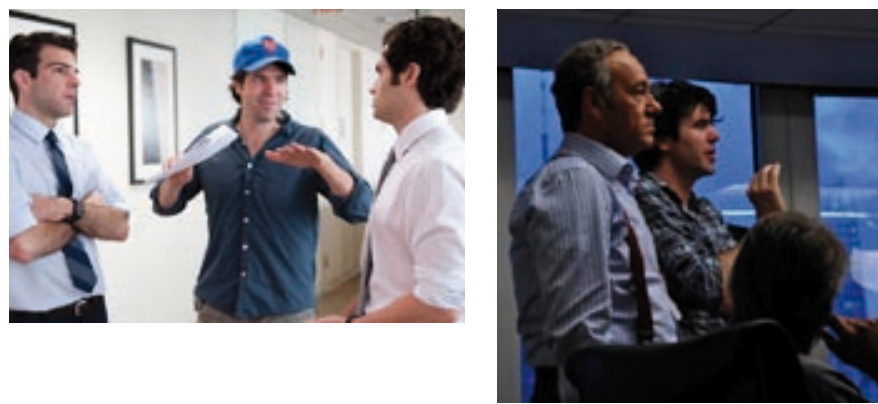

\section{ACTIVIDADES DE EXPERIENCIA, REFLEXIÓN Y ACCIÓN EN COMÚN}

Reflexionamos sobre el valor de la formación profesional, del trabajo, la ética, la amistad, el amor, la felicidad...

I. ¿Por qué creéis que el trabajo es un derecho de la persona?, ¿qué nos aporta el trabajo a nuestra vida?

2. ¿Cómo está la situación laboral en nuestro país?, ¿qué está ocurriendo y cómo se está actuando? Nos informamos en los medios de comunicación y analizamos la tasa de paro en España, en Europa, en el mundo.

3. Mediante una lluvia de ideas, exponemos un listado de sentimientos producidos en las personas que han perdido su trabajo.

4. ¿Cómo influye la falta de trabajo en una familia? Nos informamos sobre ello (prensa, radio, TV, Internet, testimonios...).

5. Dadas las circunstancias actuales, es probable que conozcáis de cerca casos de familias asociados a la pérdida de trabajo, paro, recursos económicos, pobreza, exclusión... Pensad qué actuaciones emprendedoras y solidarias podemos llevar adelante para ayudar a estas familias (intercambios de tareas y experiencias, conocimientos y alternativas de ocio y tiempo libre, consumo responsable; mercadillos, aportaciones varias...).

6. Buscamos en los medios de comunicación historias de personas sin trabajo, personas emprendedoras, asociaciones,...

7. ¿Por qué creéis que en este tipo de compañías, como las de la película, no existe actividad sindical?

8. Buscamos en el diccionario, en Internet, etcétera, el significado de los diversos términos que van apareciendo en Margin Call para entender la crisis. ¿Por qué es importante conocer conceptos económico financieros básicos?

9. Localizamos qué acontecimientos se han producido antes y después de la crisis.

10. Comentamos sobre personas conocidas que no han obrado éticamente en esta situación de crisis, ¿cómo se actúa con ellas?

II. Describimos a cada uno de los principales personajes de la película, destacamos y justificamos los valores y contravalores de cada uno de ellos, sobre sus actuaciones apropiadas e inapropiadas (Making Of. Cuadernos de Cine y Educación, 2012, n. 90$)$.

12. ¿Con qué personaje del filme os identificaríais y por qué?

13. ¿Consideráis que es importante el ocio en la vida de las personas?, ¿la gente percibe el ocio de la misma manera?, ¿qué tipo de ocio tenían los protagonistas de la película?

14. ¿Por qué es importante la ética en la formación de la persona a lo largo de su vida, en especial, en el mundo de los negocios?, ¿qué significa desempeñar nuestro trabajo con profesionalidad?

15. Buscamos y comentamos frases célebres aplicables al mundo de los negocios.

16. ¿Por qué es conveniente estar al tanto de las noticias económico financieras de nuestro entorno plasmadas en los medios de comunicación?

17. Situamos en la red escritos de Adela Cortina sobre la ética en tiempos de crisis. Seleccionamos algunos y reflexionamos sobre ellos. Os adelantamos esta frase, "La educación no puede consistir en formar personas competitivas, sino en educar ciudadanos justos" (http://elpais.com/autor/adela_cortina/a/).

18. En YouTube miramos y reflexionamos entrevistas realizadas a destacados pensadores actuales de nuestro entorno (Fernando Savater, Adela Cortina, Álvaro Pombo, Victoria Camps, José Antonio Marina...) Pienso, luego existo emitidas en La 2 de RTVE.

19. El director, J. C. Chandor, además de optar por este thriller se inclinó por realizar una película coral, ¿en qué consiste y cuáles son sus características?, ¿qué otras muestras fílmicas similares conocemos?

20. Vista y analizada Margin Call, pensaremos en sus conclusiones, ¿qué aprendizaje sacamos de ella?, ¿qué interrogantes hemos despejado sobre estos temas?, ¿nos ayudará a no repetir patrones ya pasados?

21. Conjuntamente, elaboramos unas frases de esperanza que nos faciliten la superación de esta etapa crucial esta etapa crucial por la que estamos pasando con el ánimo de percibir la luz al final del túnel. 